\title{
Uses of heparin
}

\author{
Standard heparin still the anticoagulant of choice in most clinical settings
}

Over the past 20 years many widely used drugs have been replaced by better ones. Not so heparin, which remains firmly established in the prevention and treatment of venous thromboembolism and in the treatment of unstable angina. Heparin is also the anticoagulant of choice during cardiopulmonary bypass and for haemodialysis and haemofiltration. Guidelines on the use of heparin have recently been revised by the British Society of Haematology'; they represent a balanced and authoritative view, and it is worth highlighting several points.

In some conditions the value of heparin is not as clearly established as it is in the cases described above. Controversy exists regarding the efficacy of heparin in maintaining coronary patency after thrombolytic treatment for acute myocardial infarction. The recent third international study of infarct survival (ISIS-3) showed that adding high dose subcutaneous heparin to aspirin after thrombolysis marginally reduced reinfarction and mortality during the treatment period, but this was not translated into better mortality at 35 days and six months. ${ }^{2}$ Smaller trials suggest that intravenous heparin in the same context reduces mortality, but the final answer awaits the continuing global utilisation of streptokinase and tissue plasminogen activator (alteplase) for occluded coronary arteries (GUSTO) study. ${ }^{3}$ After acute myocardial infarction (without thrombolysis), in acute peripheral arterial occlusion, and in disseminated intravascular coagulation heparin should be used selectively. For example, in disseminated intravascular coagulation heparin should be given only when manifestations are predominantly vaso-occlusive. ${ }^{1}$

Two recent studies have evaluated for how long heparin should be given for submassive venous thromboembolism, ${ }^{45}$ and a good case can be made for early oral anticoagulation and limiting heparin to four or five days. This reduces the length of hospital stay and should reduce the incidence of thrombocytopenia induced by heparin, a complication that usually occurs later (6-10 days).

Regular laboratory monitoring and the rapid achievement of therapeutic plasma concentrations of heparin are now accepted as essential for the safe and effective use of the drug. Hirsh has recently argued for the introduction of a standardised approach with the dose of heparin being adjusted according to a protocol depending on repeated measurements of activated partial thromboplastin times. ${ }^{6}$ The development of low molecular weight heparin and heparinoids has raised high and possibly unrealistic expectations that these new drugs will replace standard heparin for many of its current indications. Compared with standard heparin, low molecular weight heparins have much better bioavailability; have longer plasma half lives; and interact less with plasma proteins, platelets, and endothelial cells - characteristics which confer on these drugs possible clinical advantages. ${ }^{7}$ Although animal studies have shown that these new heparins produce less bleeding, clinical studies have generally failed to confirm these findings. Most studies have shown no clinically important difference in either efficacy or risk of bleeding between low molecular weight heparin and standard heparin used for prophylaxis against venous thrombosis for patients undergoing major general surgery, ${ }^{17}$ although a recent large study suggested fewer episodes of severe postoperative bleeding with low molecular weight heparins. ${ }^{8}$ Although these new drugs have the convenience of once daily administration, they are unlikely to replace standard heparin for this indication because of their high cost.

Low molecular weight heparins have most potential in clinical situations in which the risk of thrombosis is high and standard heparin is only partially effective. After major orthopaedic surgery low molecular weight heparins can reduce the incidence of deep vein thrombosis from $40-80 \%$ to about $15 \%$ without increased bleeding whereas with standard heparin the incidence of thrombosis remains about $25 \% .^{79}$ Similarly, they provide better prophylaxis against venous thrombosis in patients with stroke: they reduce the risk of thrombosis by $40-80 \%$ without increasing clinically important bleeding. ${ }^{70}$ Although the data are still preliminary, recent clinical trials showed that low molecular weight heparins given subcutaneously in fixed doses adjusted for weight without laboratory monitoring were as effective and safe as intravenous infusions of standard heparin with the dose adjusted according to the activated partial thromboplastin time, suggesting a potential role for anticoagulant treatment on an outpatient basis. ${ }^{9}$

In the uncommon but potentially dire thrombocytopenia induced by heparin the low molecular weight heparinoid Org 10172 (Orgaran) seems the treatment of choice to continue anticoagulation because of its lack of cross reactivity with heparin antibodies. ${ }^{11}$ Low molecular weight heparins also have drawbacks: owing to their longer half lives and poor binding to protamine their anticoagulant effect is not easily reversed in the event of bleeding or overdose. Besides, laboratory monitoring, when required, is more difficult and 
costly-simple coagulation tests such as the activated partial thromboplastin time are not sensitive enough for low molecular weight heparins and the more complex antifactor $\mathrm{Xa}$ assay is required. ${ }^{1}$

Several new antithrombotic agents such as hirudin and its derivatives are currently under investigation. Future clinical studies will determine whether they are more effective and safe than low molecular weight heparins and standard heparin.

\section{N CHESTERMAN} Professor

B H CHONG Professor

Centre for Thrombosis and Vascular Research, University of New South Wales,

Department of Haematology,

Prince of Wales Hospital,

Sydney NSW 2000,

Australia
1 Colvin BT, Barrowcliffe T. The British Society for Haematology guidelines on the use and monitoring of heparin 1992: second revision. F Clin Pathol 1993;46:97.

2 ISIS-3 (Third International Study of Infarct Survival) Collaborative Group. ISIS-3: a randomised comparison of streptokinase vs tissue plasminogen activator vs anistreplase and of aspirin plus heparin vs aspirin alone among 41299 cases of suspected acute myocardial infarction. Lancet 1992;339:753-70.

3 Streptokinase plus aspirin does the trick: ISIS-3 [editorial]. Lancet 1992;339:780-1.

4 Gallus AS, Jackaman J, Tillett J, Mills W, Wycherley A. Safety and efficacy of warfarin started early after submassive venous thrombosis or pulmonary embolism. Lancet 1986;ii:1293-6.

5 Hull RD, Raskob GE, Rosenbloom D, Panju AA, Brill-Edwards P, Ginsberg JS, et al Heparin for 5 days as compared to 10 days in the initial treatment of proximal venous thrombosis. $N$ Engl $f$ Med 1990;322:1260-4.

6 Hirsh J. Heparin. N Engl f Med 1991;324:1565-74.

7 Hirsh J. Overview of low molecular weight heparins and heparinoids: basic and clinical aspects. Aust NZ F Med 1992;22:487-95.

8 Kakkar VV, Cohen AT, Edmonson RA, Phillips MJ, Cooper DJ, Gas SK, et al. Low molecular weight versus standard heparin for prevention of venous thromboembolism after major abdominal surgery. Lancet 1993;341:259-64.

9 Planes A, Vochelle N, Mazas F, Mansat C, Zuckman J, Landais E, et al. Prevention of postoperative venous thrombosis: a randomised trial comparing infractionated heparin with low molecular weight heparin in patients undergoing total hip replacement. Thromb Haemost 1988;60:407-10.

10 Turple AGG. Orgaran in the prevention of deep vein thrombosis in stroke patients. Haemostasis 1992;22:92-8.

11 Chong BH, Ismail F, Cade J, Galius AS, Gordon S, Chesterman CN. Heparin-induced thrombocytopenia: studies with a new low molecular weight heparinoid, Org 10172. Blood 1989;73:1592-6.

\section{Commissioning specialist services}

\section{Problems ahead in the regions}

The commissioning of highly specialised clinical or support services has never been straightforward. As some such services are of national importance it was sensible for the government to establish a means of addressing the problem. In 1983 the Department of Health set up the Supra Regional Services Advisory Group to consider proposals for clinical services which, to maximise the benefit to patients and yet ensure the maintenance of skill and economic operation, would need to be provided to populations of five million or more. The criteria were set out in a health circular, ${ }^{1}$ which was subsequently updated. ${ }^{2}$

Every new bid submitted via the regional health authority to the advisory group is first considered by the relevant college or faculty before any recommendation is made to the secretary of state. The expansion or devolution of centrally funded services also requires constant review-for example, spinal injury units were dedesignated last April. About $£ 100 \mathrm{~m}$ is designated for supraregional services each year, with allocations for individual specialties varying from $£ 500000$ upwards, although three services absorb over half the allocation. The identity of these supraregional services, together with their financial allocations, is open to public comment through the publication of an annual report ${ }^{3}$ and written answers given in Hansard to parliamentary questions.

With slightly varying definitions of what constitutes a specialty, similar arrangements have been in place for many years in each of the 14 English regional health authorities. These specialties usually serve populations of less than five million but more than would be appropriate in most districts or provider units. Most regions have identified as regional specialties services such as radiotherapy, neonatal intensive care, neuroscience, renal dialysis and transplantation, cardiothoracic surgery, and, more recently, clinical genetics. The principles underlying these services are that they should be in the right place, proliferation should be avoided, and they should handle enough work to ensure the maintenance of skills for patient care, teaching, and research and economics of scale. Regional health authorities have always had to be alert to the possible overprovision of these services to the local communities in which they are located and to the converse problem of inadequate access from other parts of the region.
Proposed changes have been subject to wide consultation with the district health authorities and the professions, and the decisions have been open to public observation.

Since April 1991 regions have been devolving these services to the district health authorities, and in most cases some form of protection has applied, at least for the first financial year. Donaldson recently described a range of contracting models of the services that might be suitable for different types of contracts. ${ }^{4}$ But there are signs of trouble ahead, which, if not addressed now, could cause irretrievable harm not just to existing but also to future services.

The consortium model, in which one district health authority purchaser within the host region acts on behalf of others, appears efficient in principle because the regional specialty director has to deal with only one body. The purchaser is assumed to understand the subject clearly and to be able to negotiate on behalf of the wider population. The reality is proving to be very different. Providers are being told that any expansion or other important changes in the services must be negotiated with each purchasing authority separately. Each purchaser, moreover, is demanding evidence of value for money from the current service. Thus the provider, usually the director of the unit, acquires the time consuming burden of satisfying all the parties and begging them to come to his or her way of thinking for the future.

Where the purchasing authorities are acting on their own the provider unit has to negotiate with each one. Even then, however, the situation can be fraught with danger and worry. Purchasing authorities vary enormously in size, knowledge, and desire for change. For example, whereas a large purchasing authority in London may well be able to select from many providers for a particular regional specialty the remaining purchasers in the same region may depend on the large purchaser maintaining a contract with one particular provider to ensure a sufficient volume of service to be effective and competitive. Nor may the other purchasers have any realistic alternative choice of provider for such a service. The specialty reviews, following on from the Tomlinson report, will constantly need to bear in mind the recipients of the services if they are not to allow the views of the powerful purchasers to dominate their decisions. Even worse would be a harmonious 